
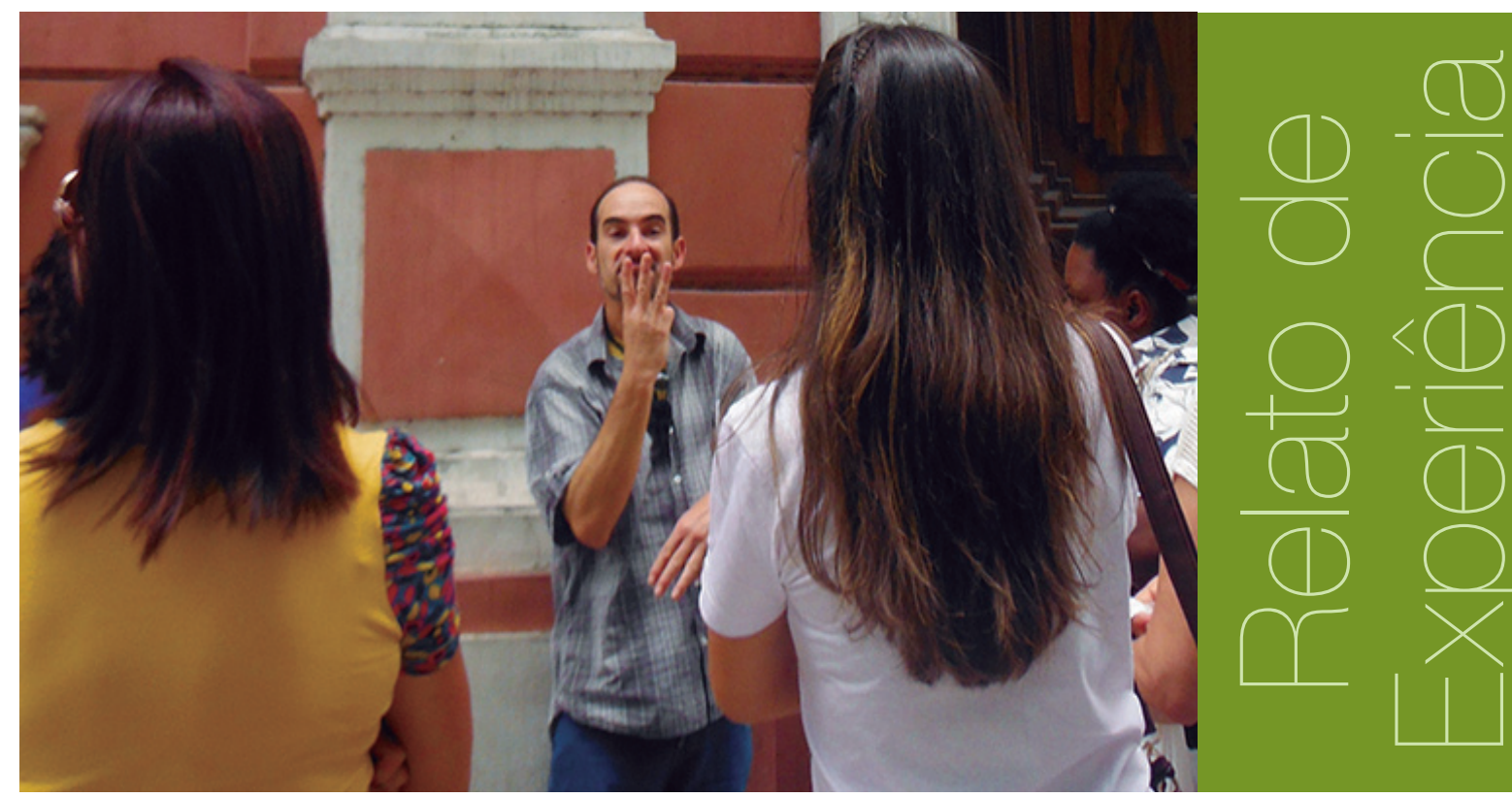

\title{
Aprendendo Libras: Uma segunda língua, uma nova cultura
}

\author{
Maria Helena Alemany Soares ${ }^{1}$ - maria.helena@ifsc.edu.br \\ Joel Aroldo Pereira² - joel.hallow@gmail.com
}

\section{RESUMO:}

0 projeto de extensão "Curso de Formação Inicial e Continuada em Língua Brasileira de Sinais - Libras nível Básico" buscou promover a capacitação de servidores públicos (municipais, estaduais e federais) que trabalham em instituições culturais, para que os mesmos possam vir a atuar no recebimento do público surdo nesses estabelecimentos. A oferta do curso básico de Libras permitiu a qualificação profissional dos participantes e o fortalecimento da acessibilidade comunicacional à comunidade surda.

\section{PALAVRAS-CHAVE:}

Surdos. Libras. Inclusão. Capacitação. Espaços Culturais.

\section{ABSTRACT}

The extension project "Initial Course and Continuing Qualification in Brazilian Sign Language LIBRAS basic level" sought to promote the training of public officials (municipal, state and federal) working in cultural institutions, so that they can act upon the reception of the deaf audience in these establishments. The offer of the basic course in LIBRAS, allowed the qualification of the participants and the strengthen of communication accessibility to the deaf community.

\section{KEYWORDS}

Deaf. Libras/Brazilian Sign Language. Inclusion. Qualification. Cultural Centers.

\footnotetext{
1 Graduada em Licenciatura - Educação Artística e Formada no Curso Técnico em Guia de Turismo Categoria - Regional Santa Catarina. Docente e Coordenadora do Curso Técnico Guia de Turismo no Câmpus Florianópolis-Continente do IFSC

2 Bolsista do Projeto de Extensão - Curso Básico de Libras - Bacharel em Jornalismo e Estudante de Guia de Turismo no Câmpus Florianópolis-Continente do IFSC
} 


\section{Introdução}

0 projeto de extensão "Curso de Formação Inicial e Continuada - Libras Básico", executado pelos câmpus Palhoça-Bilíngue e Florianópolis-Continente em parceria com a Casa da Memória de Florianópolis, foi realizado no segundo semestre de 2013, tendo como objetivo qualificar e capacitar servidores municipais, estaduais e federais que atuam em instituições culturais na aquisição da Língua Brasileira de Sinais - Libras, assim como, promover a acessibilidade comunicacional do público surdo junto a essas instituições de cultura.

0 curso surgiu da demanda observada na conclusão do projeto de pesquisa intitulado "A Inclusão do Surdo nos Espaços Culturais Turísticos de Florianópolis", publicado em 2013, pela editora Arara Azul e produzido entre 2011 e 2012 por docentes e aluno bolsista do IFSC. A pesquisa apontou que o público surdo prefere ter acesso a informação por meio de Libras, seja por servidor fluente na língua de sinais, por intérprete ou vídeos em Libras que repassem as informações do atrativo cultural (Soares et al, 2013). Ademais, foi observado que as instituições culturais não possuem servidores capacitados para suprir a demanda no que tange à acessibilidade comunicacional para o público surdo, apesar da legislação estar adequada a essa parcela da população.

0 IBGE revelou que o número de surdos no Brasil era de 9,7 milhões de pessoas (IBGE, 2010 e INEP, 2006), sendo que desses, aproximadamente 24.961 vivem na Grande Florianópolis. Deste universo, $97,53 \%$ dos surdos estão fora das creches, $86,28 \%$ estão fora da educação infantil e ensino fundamental, $96,15 \%$ estão fora do ensino médio e 99,06\% estão fora do ensino superior, conforme análises e dados apresentados pelas instituições.

Esta conclusão acontece pelo impasse comunicacional entre surdos e ouvintes. Dentro deste contexto, além da capacitação profissional proposta, o projeto contribui para o reconhecimento da Língua Brasileira de Sinais, essa que é respaldada pela Lei no 10.436, de 24 de abril de 2002 e regulamentada pelo Decreto $n^{0} 5.626$ de 22 de dezembro de 2005.

\section{2 ○ projeto e sua execução}

Com 0 objetivo de capacitar profissionais que atuam em locais de cultura, no quesito acessibilidade comunicacional, foi elaborado um curso de Libras-Básico, com duração de 80 horas. Foi realizada uma parceria entre os câmpus do IFSC Palhoça-Bilíngue e FlorianópolisContinente com a Casa da Memória de Florianópolis, sendo o IFSC responsável por coordenar a oferta do curso, disponibilizar corpo docente, realizar a seleção e certificação dos alunos. Já a Casa da Memória assumiu o compromisso de ceder o local e equipamentos multimídia para a realização das aulas.

Com isso, o IFSC lançou o Edital 16/DEING/2013/2 de Curso de Qualificação - FIC (Formação Inicial e Continuada em Curso Básico em Libras), com 20 vagas, e obteve 38 inscritos. Além dos servidores das instituições culturais, houve uma grande procura por parte da comunidade civil: três guias de turismo, um condutor ambiental, duas estudantes do IFSC, três educadores, dois profissionais liberais. 0 bolsista e a coordenadora do projeto também participaram da capacitação com o objetivo de acompanhar o andamento do curso e iniciar o aprendizado na área.

A execução do projeto ocorreu de agosto a dezembro de 2013 - com atividades todas as segundas-feiras no período vespertino. Com base em registros, passaram pelo projeto 20 alunos e 13 finalizaram o curso.

\section{A participação e retorno da comunidade}

A primeira aula foi uma palestra do professor de Libras e diretor do Campus Palhoça-Bilíngue, com tradução de uma intérprete, representantes da Casa da Memória e a coordenadora do projeto de extensão. Finalizado o curso, a evasão dos alunos foi notada; pois dos 20 alunos participantes, quatro comunicaram formalmente a desistência, uma aluna realizou a matrícula, 
mas nunca frequentou as aulas, três obtiveram um número elevado de faltas e os demais concluíram o curso com frequência e aproveitamento adequados com a proposta do curso.

Além disso, o professor disponibilizou uma cartilha denominada "Aprendendo Libras como Segunda Língua", editada pelo IFSC, e fez a indicação de um aplicativo "Dicionário em Libras" para celulares e tabletes que funcionam com sistema operacional android e IOS, tudo para que os alunos pudessem dar continuidade aos estudos fora do ambiente de ensino.

Dentre as atividades executadas com os alunos, os professores abordaram, além do ensino de Libras, a vivência e a cultura surda, sendo explanadas curiosidades e informações relevantes ao tema. As aulas seguiram com dinâmicas de grupos, apresentação de vídeos com a temática surda e interações por meio de diálogos em Libras.

Durante o curso, foi realizada visita técnica aos Museus Victor Meirelles e Museu Histórico de Santa Catarina - Palácio Cruz e Sousa, conforme as figuras 1 e 2, com 0 intuito de observar e tirar dúvidas dos servidores em capacitação nos seus respectivos ambientes de atuação profissional.

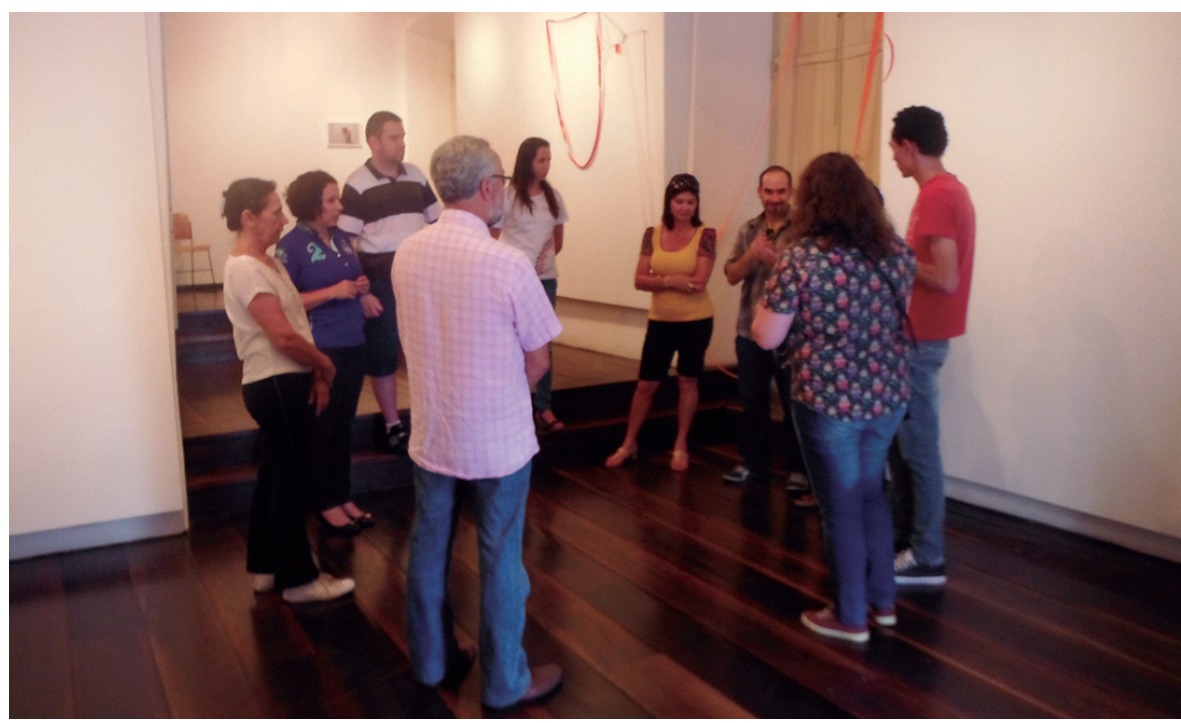

Figura 1: Visita ao Museu Victor Meirelles

Fonte: Arquivo Coordenação

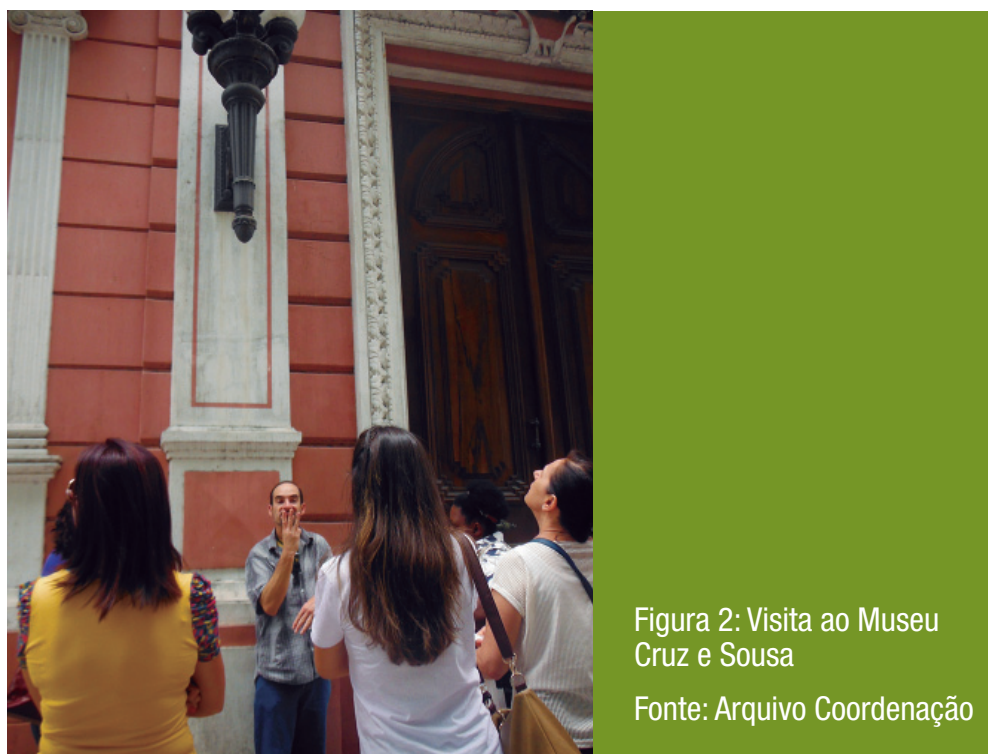

Destaque para o Museu Victor Meirelles que, ao pensar no atendimento ao público surdo, submeteu por meio do Edital da Caixa Econômica Federal, o Projeto "Ver e Ouvir Victor Meirelles", o qual foi contemplado com recursos para a produção e compra de "vídeos guias", no qual apresenta o museu e as principais obras da instituição em Libras, espanhol, inglês português e francês. (Figura 3). 
Figura 3: Vídeo Guia em Libras

Fonte: Arquivo Coordenação

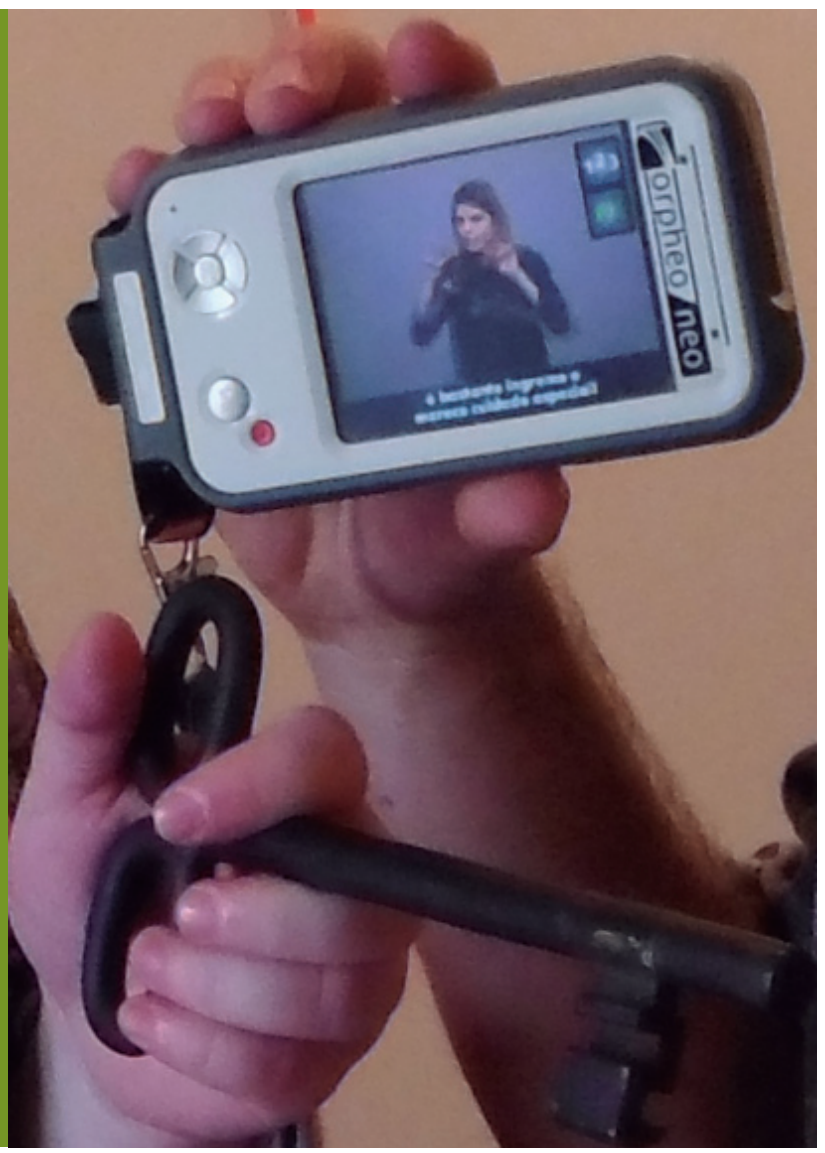

Um questionário semiestruturado foi realizado com os alunos para saber as opiniões desses em relação ao aprendido. Praticamente todos os opinários respondidos consideraram que projetos dessa natureza são relevantes não somente para os funcionários, mas para toda a comunidade, tanto surda, como dos ouvintes, e que tinham um grande interesse em dar continuidade ao curso, sendo a participação do IFSC e a Casa da Memória fundamentais para essa continuidade.

Dentre os comentários e observações elencadas pelos participantes, pode-se apontar:

Todo novo conhecimento é bem-vindo, e foi muito válido para mim, pois, para a instituição [em que trabalho] é muito importante ter um funcionário que saiba a Língua de Sinais. Quero continuar a aprender mais.

0 curso foi útil, mas vejo a necessidade de continuidade para que tenhamos segurança em Libras, para consequentemente [ter] desdobramento profissional e pessoal.

A divulgação do projeto foi realizada previamente em diversos estabelecimentos culturais e quando lançado o Edital foi realizado contato telefônico e por e-mail com todas as instituições que apresentaram interesse em participar do curso.

\section{Considerações Finais}

Analisando os resultados deste projeto de extensão, verificou-se que as metas e o objetivo geral foram alcançados, entretanto em partes, tendo em vista que 0 aprendizado de uma nova língua demanda tempo, prática e dedicação, sendo que a continuidade dos estudos é fundamental para a fluência no idioma.

Com isso, cientes da demanda pela continuação do curso de Libras, uma solicitação formal de continuidade foi protocolada, aceita pelas instituições e a oferta do novo Curso de Libras Intermediário teve início em março de 2014.

Este projeto sinaliza positivamente a capacitação dos servidores de instituições culturais, assim como sociedade civil. Com isso, cumpre-se o previsto na legislação, além de oferecer autonomia ao público surdo de visitar espaços culturais do centro de Florianópolis. 
A junção de projetos de pesquisa e extensão é fundamental para a sociedade em geral, pois, além de provar demandas reais e realizar a capacitação analisada é primordial no que tange as instituições de ensino e cultura.

Espera-se que essa capacitação realizada via projeto de extensão possa inspirar os órgãos públicos em suas diferentes atuações, e assim, possibilitar uma melhor interação entre a comunidade local e públicos especiais.

\section{Referências bibliográficas}

ALMEIDA, Wolney Gomes. Surdez e Cidadania: Um olhar sobre a inclusão social e as políticas públicas no contexto turístico. Dissertação (Mestrado em Cultura e Turismo) - Universidade de Santa Cruz, Ilhéus, 2008.

BRASIL, Lei $\mathbf{1 0 . 4 3 6}$ de 22 de abril de 2002. Reconhece a Língua Brasileira de Sinais, Libras.

BRASIL, Decreto-Lei 5.296 de 02 de dezembro de 2004. Regulamenta as Leis nos 10.048, de 8 de novembro de 2000, que dá prioridade de atendimento às pessoas que especifica, e 10.098, de 19 de dezembro de 2000, que estabelece normas gerais e critérios básicos para a promoção da acessibilidade das pessoas portadoras de deficiência ou com mobilidade reduzida, e dá outras providências.

BRASIL, Decreto-Lei 5.696 de 22 de dezembro de 2005. Regulamenta a Lei no 10.436, de 24 de abril de 2002, que dispõe sobre a Língua Brasileira de Sinais - Libras, e 0 art. 18 da Lei no 10.098, de 19 de dezembro de 2000.

GESSER, Audrei. Libras que Língua é essa? - Crenças e Preconceitos em Torno da Língua de Sinais e da Realidade Surda. São Paulo: Parábola, 2009.

INSTITUTO BRASILEIRO DE GEOGRAFIA E ESTATÍSTICA. Censo demográfico 2010: Resultados preliminares da amostra. 2010. Disponível em: <http://deficientefisico.com/ resultados-do-censo-2010-feito-pelo-ibge-sobre-pessoas-com-deficiencia>. Acesso em 22 dez. 2013.

SOARES, Maria Helena Alemany. et al.: A Inclusão do Surdo nos Espaços Culturais Turísticos de Florianópolis. Petrópolis: Arara Azul, 2013 